\title{
Changes in haematological indices following local application of interleukin-1 receptor antagonist protein after tenotomy in rabbits
}

\author{
Marko Pecin, Marija Lipar, Ozren Smolec, Boris Pirkic, Andrija Musulin, Josip Kos \\ University of Zagreb, Faculty of Veterinary Medicine, Department of Surgery, Orthopaedics and \\ Ophthalmology, Zagreb, Croatia \\ Received March 3, 2016 \\ Accepted May 31, 2017
}

\begin{abstract}
Interleukin-1 (IL-1) is the most important cytokine in the inflammation cascade activation in all tissues and is present in acute and chronic phases of inflammation. By blocking IL-1 binding to target cells, numerous inflammation processes are prevented. The use of autologous conditioned serum rich with IL-1 receptor antagonist protein (IL-1Ra) is a novel treatment method of tendon inflammation in domestic animals and humans. Injections of autologous conditioned serum (ACS) have demonstrated clinical efficacy and safety in animal models and humans in the treatment of osteoarthritis, disc prolapse and muscles and tendons injuries with low side effect. Neutropaenia, reduced white blood cell count, and infections or local irritations are described as side effects of IL-1 antagonist use in humans. Therefore, a study of blood changes in rabbits after local administration of IL-1Ra in the Achilles tendon tissue after iatrogenic inflammation was conducted. Interleukin-1 receptor antagonist protein was used to prevent and reduce tendon inflammation after longitudinal tenotomy. The study was done on 26 white Californian rabbits, divided into two equal groups consisting of 13 animals each; the experimental interleukin-1 receptor antagonist protein (irap) group, and the control group. In the irap group, autologous serum rich with IL-1Ra was used (Orthokine ${ }^{\mathbb{R}}$ vet irap, Alfa-Arthro, Croatia). Differences between two groups were considered significant as changes in the blood for certain blood elements at $P<0.01$. The $P$ value was $P=0.0153$ for the white blood cells, $P=0.00153$ for neutrophils, $P=0.00017$ and for platelets. In the control group, an increased platelet count was noticed in $70 \%$ of blood samples and a decreased neutrophil count was found in all of the irap group samples at the end of the study in comparison to the initial blood count prior to application.
\end{abstract}

Receptor antagonist, thrombocytosis, neutropaenia, Achilles tendon, inflammation, rabbits

Interleukin-1 (IL-1) is an important cytokine in the inflammation cascade activation in all tissues. It is present in acute and chronic phases of inflammation and has influence on its onset and outcome. The blocking of IL-1 binding to target cells prevents numerous diseases. The discovery of new methods of tendon injury treatment contributed to faster recovery and improved final outcome of treatment. In recent years, autologous conditioned serum (ACS) has been frequently used in the treatment of inflammatory diseases of the joints, muscles and tendons in humans and also in animals. The use of autologous conditioned serum rich with IL-1 receptor antagonist protein (IL1-Ra) from Orthokine ${ }^{\mathbb{E}}$ vet (irap ${ }^{\circledR}$ Alfa-Arthro, Croatia) is a novel method of treatment inflammation of the tendons in domestic animals and humans. It contains large quantities of IL-1 antagonist (IL1-Ra) with very low concentration of other cytokines and growth factors compared to that found in other available blood derivatives and products such as platelet rich plasma (PRP) or other ACS incubated for $24 \mathrm{~h}$. Shorter incubation period of 6-9 h concentrates only the level of IL-1Ra. Therefore, its target is mainly deactivation of IL-1beta by binding antagonist on the same receptors on target cells. Injections of ACS have demonstrated clinical efficacy and safety of use in animal models and humans in the treatment of osteoarthritis (Kos et al. 2012), intervertebral disc prolapse, and muscle and tendon injuries (Wehling et al. 2007). Also ACS has been more frequently used in the treatment of acute and chronic

Address for correspondence:

Marko Pecin

Department of Surgery, Orthopaedics and Ophthalmology

University of Zagreb

Heinzelova 55, 10000 Zagreb, Croatia
Phone: +385912390161

Fax: +38512390380

E-mail: mpecin@vef.hr

http://actavet.vfu.cz/ 
inflammation of the musculoskeletal system in horses (Textor 2011). Wright-Carpenter et al. (2004) have proved a positive effect of autologous conditioned serum in accelerating the healing of muscle injuries in mice by applying ACS in muscle contusions by model. In animal models and in clinical tests on animals, blockade of IL-1 with IL-1Ra slowed down the progression of some pathological conditions. IL-1Ra has proven to be effective as a method of treatment and alleviation of symptoms of osteoarthritis in rat models after local intra-articular application or gene transfer injection (Evans et al. 2004). The same effect was observed in dogs (Pelletier et al. 1997), rabbits (Fernandes et al. 2002), and horses (Frisbie et al. 2002). Zhang et al. (2011) have demonstrated the effectiveness of intra-articular application of IL-1Ra in reducing the symptoms and improved osteoarthritis treatment of the temporomandibular joint in humans. However, neutropenia, reduced white blood cell count and infections or local irritations are described as side effects of IL-1 antagonist (anakinra, Kineret ${ }^{\mathbb{R}}$ ) use in humans. Today, the treatment of acute and chronic inflammation of the tendons is generally conducted with corticosteroids and nonsteroidal anti-inflammatory drugs (NSAIDs). However, this type of treatment removes only the consequences of inflammation while the cause remains often unexplored or undiscovered. Therefore, controversial use of NSAIDs and corticosteroids is not the right choice for treatment of tendon disorders (Rees et al. 2006).

As mentioned earlier, the use of IL-1 antagonist in humans had a negative side effect on the complete blood count and neutrophil concentration in blood. The monitoring of blood indices is therefore vital for understanding the negative side effects of IL-1Ra use in rabbits and its comparison to normal physiological blood values. Those values were different in rabbits depending on the age and type, sex and stage of gestation, according to many authors. The values vary, and the mean concentrations were as follows; for red blood cells (RBC) 3.8 to $7.9 \times 10^{\wedge} 12 / 1$, haemoglobin 10-15 g/dl, white blood cells (WBC) 5-13 $\times 10^{9} / 1$, cells $2.8-5.6 \times 10^{\wedge} 9 / 1$, thrombocytes $125-270 \times 10^{\wedge} 9 / 1$, neutrophils from 1.7 to 9.1 $\times 10^{9} / 1$ (Mirutka and Rawnley 1977; Kerr 1989; Fudge 1999). Hewitt et al. (1989) extracted blood from 110 New Zealand White rabbits and determined the average value of blood cells. So WBC averaged $9.2 \times 10^{\wedge} 9 / 1(5.2$ to 16.5$)$, erythrocytes $6.0 \times 10^{12} / 1(3.7$ to $7.5)$, haemoglobin $12.8 \mathrm{~g} / \mathrm{d}(8.9$ to 15.5$)$, platelets $132 \times 10^{\wedge} 9 / 1(112-795)$. Similar surveys have been released by Archetti et al. (2008) built on the previous survey by Hewitt et al. (1989). Physiological values of erythrocytes, platelets and haemoglobin were mostly the same, and the mean value of neutrophils amounted to $3.6 \times 10^{\wedge} 9 / 1(0.7$ to 8.5$)$ and for lymphocytes $2.1 \times 10^{\wedge} 9 / 1(0.5$ to 6.4$)$.

\section{Materials and Methods}

The study was approved by the Ethics Committee of the Faculty of Veterinary Medicine and the Ministry of Agriculture in Zagreb, Croatia. It included 26 white Californian rabbits, randomly divided into two groups; the irap and the saline group, each containing 13 rabbits ( 7 males, 6 females), of 2 years of age and the mean body weight of $3 \mathrm{~kg}$. Rabbits were held in metal cages of the dimensions $85 \times 64 \times 68 \mathrm{~cm}$, on litter, two rabbits per cage. Water and food were provided ad libitum. Twice daily they were let in open stables for one hour. Blood was taken from each rabbit in the irap group in a commercial sterile irap ${ }^{\circledR} 10 \mathrm{ml}$ syringe (Orthokine ${ }^{\circledR}$ vet irap, Alfa-Arthro, Croatia), using a closed venipuncture system. Syringes were stored in an incubator at $37^{\circ} \mathrm{C}$ for approximately $6 \mathrm{~h}$ and subjected to the process of centrifugation at $3000 \mathrm{~g}$ for $10 \mathrm{~min}$ in order to separate the serum from the blood cellular elements. Centrifuging resulted in conditioned serum containing large quantities of anti-inflammatory autologous interleukin-1 receptor antagonist protein (IL-1Ra) without significant changes in the concentration of other cytokines and growth factors as in other commercial products such as platelet rich plasma (PRP) or other blood derivatives. Also blood was taken for a complete blood count one day prior to surgery in both groups through the ear vein using the closed venipuncture system.

In both groups of animals after intramuscular sedation with ketamine and xylazine and epidural anaesthesia with $2 \%$ lidocaine and general inhalation anaesthesia with $2 \%$ sevoflurane applied trough mask, posteromedial skin incision was made. Surrounding tissue and tendon sheath resection was made following scarification and tenotomy of the Achilles tendon along the entire length of tendon with surgical blade No.15 with three parallel cuts. Longitudinal tenotomy induced inflammation of the tendon tissue as described in earlier studies 
(Friedrich et al. 2011). Tendon sheaths were reconstructed and sutured with polyglconat 3-0 USP (Maxon ${ }^{\mathrm{TM}}$, Medtronic Covidien, Switzerland) and the skin was reconstructed with a nylon suture 4-0 in both groups. Irap was administered in the irap group $\times 3$ in the first $48 \mathrm{~h}$ after surgery using the irap ${ }^{\circledR}$ system, using a sterile syringe in $1.8 \mathrm{ml}$ in total through a sterile biological filter $(0.22$ microns pore size $)$. Purified buffered saline (PBS) was administered in the control (saline) group in the same places, at the same volume, using the same application technique and in the same time intervals. The first application was after the tendon sheath reconstruction, the second after $24 \mathrm{~h}$, and the last $48 \mathrm{~h}$ after surgery. The dosage was $0.6 \mathrm{ml}$ per application, and it was applied in three positions in the tendon; by tendomuscular insertion $(0.2 \mathrm{ml})$, in the middle of the tendon $(0.2 \mathrm{ml})$, and $5 \mathrm{~mm}$ above the junction with the calcaneus $(0.2 \mathrm{ml})$.

It has already been mentioned in research methods that blood samples were taken one day before the start of the study. Blood was also taken on the day of the sacrifice in order to compare the blood values between the two groups at the beginning and at the end of the experiment. The blood samples were taken aseptically from the ear vein. Blood work was done by the LaserCyte analyzer (IDEXX VetLab ${ }^{\circledR}$, Netherlands) in a laboratory at the Department of Surgery, Orthopaedics and Ophthalmology, University of Zagreb. Concentration of IL-1 was measured by using ELISA kit for rabbit IL-1 provided by R\&D Systems ${ }^{\mathbb{R}}$, USA.

Prior to IL-1Ra application, it was important that the rabbits were free of clinical and detectable haematological signs of infection, especially a reduced number of neutrophils and total count of white blood cells. As mentioned before, neutropenia and reduced white blood cell count are described as side effects of IL-1 antagonist use in human clinical patients. For these reasons, effects of IL-1Ra on the complete blood count and neutrophil changes in the blood were measured in rabbits. Therefore, prior to the start of the trial, research physiological values of complete blood counts in the rabbit species were obtained.

The statistical analysis was made using a personal computer system SPSS for Windows XP. To compare the groups, a descriptive statistics (n, standard deviation, the arithmetic mean) were used and calculated for all indicators. The results were statistically analysed using the STATISTICA software to compare the difference between the two test groups. Mann-Whitney U-test, Wilcoxon test, and $t$-test were used, considering that there were a small number of mutually dependent samples. Results were considered significant at $P<0.01$.

\section{Results}

Longitudinal tenotomy caused inflammation that had a positive influence on increased IL- $1 \beta$ concentration in the control group of Achilles tendons. The concentration was $\times 2.5$ higher compared to the irap group. IL-1Ra in the irap group reduced IL-1 concentration in the tendon tissue and had a positive influence on lower IL-1 concentration 4 weeks after application. Also, there were significant changes in blood samples between the two groups taken one day before the trial, and 4 weeks after. In the current study, only one rabbit in the irap group had a neutrophil count of $0.52 \times 10^{\wedge} 9 / 1$ which is below the physiological limit for adult rabbits $\left(0.7\right.$ to $\left.8.5 \times 10^{\wedge} 9 / 1\right)($ Archetti et al. 2008). The value was almost $\times 9$ lower, and the decline was noticeable because of the initial value of $4.59 \times 10^{\wedge} 9 / 1$. In the same specimen, a noticeable 6-fold decrease in the white blood cell count below the lower physiological threshold at $5.2 \times 10^{\wedge} 9 / 1$ (Hewitt et al. 1989) was observed with normal erythrocyte and haemoglobin values. In another rabbit, a remarkable decline in the number of neutrophils by more than $\times 4$ was noticed from the initial value of $8.75 \times 10^{\wedge} 9 / 1$ to $1.95 \times 10^{\wedge} 9 / 1$ at the end. The mean number of neutrophils in the irap group was within the normal range, reaching $2.31 \times 10^{\wedge} 9 / 1$. The drop in the number of neutrophils was noted in the blood of all rabbits in the irap group after 4 weeks of the study.

All rabbits showed an increased number of platelets compared to the initial state. Only two animals showed a slight increase of the platelet count in the upper physiological limit, which is $650 \mathrm{~K} / \mu \mathrm{l}(250$ to 650$)$, without crossing those values. In the control group, there was no significant difference between the blood test results at the beginning and at the end of the experiment except for the platelet and white blood cell values. In contrast to the value of the platelet in the irap group which was increased but still within the physiological range, the control group at the end of the study showed a noticeable increase in the platelet count values over the upper physiological limit in $70 \%$ of animals $(P=0.000713)$. Platelet counts increased significantly $\times 2.4$ on average, compared to the initial value. The increase in white blood cells was seen in $90 \%$ of control group blood samples with significant changes $(P=0.0075)$. Significant differences were considered as changes in the blood for 
certain elements which had the $P$ value lower than or equal to $0.01(P \leq 0.01)$. The $P$ value was $P=0.0153$ for the white blood cells (WBC), $P=0.00153$ for neutrophils (NEU), and $P=0.00017$ for platelets (PLT). The present neutrophilia was not significant $(P=0.085)$. Other values were maintained within the physiological range according to Hewitt et al. (1989) for mature rabbits. Local infection at the site of administration of the ACS or PBS was not observed. There were no signs of chronic sepsis where the number of neutrophils is lower than physiological value.

\section{Discussion}

All animals in the irap group had the number of neutrophils decreased several times from the initial value, which can be a side effect of using autologous serum just as in humans (Perlmutter et al. 2001). The increase in the platelet count over the physiological range in the control group at the end of the study was in $70 \%$ of the tested animals $(P=0.00713)$. Such increase could be due to inflammatory diseases such as bacteraemia and systemic infection with Pasteurella multocida (Ruble et al. 1999). Also, disturbance in the connective tissue, inflammatory conditions such as tendonitis of Achilles tendon as a result of longitudinal tenotomy can increase the serum platelets count. Since the blood tests and local findings on tendons showed no signs of infection and changes characteristic of $P$. multocida infection, and were with the absence of reduction in the number of platelets characteristic for the acute inflammation in rabbits (Vennen and Mitchell 2009), it was concluded that the increased number of platelets can be a result of an inflammatory reaction of the tendinous tissue or direct influence of IL- 6 on thrombocytopoesis. This conclusion was possible due to the known fact that IL-6 is responsible for the thrombopoetin activation and therefore subsequent thrombocytosis (Kaser et al. 2001). Since it is known that IL-1 activates the IL-6 (Tosato and Jones 1990; Dhamija et al. 2011), which consequently activates the platelet-derived growth factor (PDGF) and secretion of other cytokines, it is possible that IL-1Ra in the irap group was indirectly responsible for the decrease of the platelet count. Such IL-1Ra action could reduce indirectly the effect of IL-6 by inhibiting IL-1. The higher the number of platelets in the control group could be due to the increased concentrations of IL- $1 \beta$ in serum and its aforementioned indirect positive effect on thrombocytosis through IL-6 activation. In the control group, an increased number of white blood cells were observed in $90 \%$ of blood samples with significant changes $(P=0.0075)$. In rabbits, the number of white blood cells is uncommon in infections but also could be related to stress (Melilla 2007) and in the routine blood tests sampling (Harkness and Wagner 1995) where primarily increased neutrophil and lymphocyte count was noticed (Jain 1986). Since the same stress was possible during blood sampling in both groups, stress was eliminated as causative factor of increase WBC count. Since the number of white blood cells (WBC) was normal, or reduced, except for neutropaenia, the increase of white blood cells in the control group must have had a different cause. IL-1 $\beta$ can induce neutrophilia as a non-specific immune response (Shi et al. 1994). If we consider that the amount of IL- $1 \beta$ in the serum of the control group was higher, it could increase the number of white blood cells. Four weeks after the local application of autologous serum in the irap group, the previously mentioned neutropaenia, a reduced white blood cell count, a slight decrease in haemoglobin and lymphocytes as well as an increased count of platelets were observed. The findings were consistent with the findings reported in a presentation by Permutter et al. (2001). In this presentation, the side effects of the anakinra (recombinant human IL-1 receptor antagonist) in humans were described. Those changes were noticed as a reduced number of neutrophils and total white blood cell count after 4 weeks of the use of the antagonist. In the presentation, only $0.04 \%$ of cases had a strong neutropaenia $\left(<0.5 \times 10^{\wedge} 9\right)$. The reduced number of neutrophils was mostly 
under $2.0 \times 10^{\wedge} 9$ (physiological $4 \times 10^{\wedge} 9 / 1$ ), noticed in $62.5 \%$ of patients. Infection did not occur in human patients but local reaction at the site of anakinra application in the form of erythema, pain and oedema were observed. Sensitivity reactions of the treated area disappeared in a few days, and the neutrophil values returned to normal range after 10 days. Therefore, local inflammatory reactions at the application site of the recombinant IL-1 antagonists are common and have been observed in approximately $50 \%$ of patients. Also it was noted that the incidence of serious infections occurred more frequently in patients treated with anakinra (Fleischman et al. 2003). Since the tested animals in our study did not show evidence of systemic or local infection, wounds were clean and without discharge, the skin in the area of the Achilles tendon had same temperature as the rest of the body, was painless to touch, bacterial infection was ruled out at the site of application, and the local irritation and reaction of the surrounding tissue of the Achilles tendon can be attributed to the local administration of the autologous serum. Other authors have stated that in humans following topical application of similar preparations of IL-1 receptor antagonist and autologous serum pain, inflammation or erythema occurred in $70 \%$ of cases (Fleischman et al. 2003).

Despite a positive influence on reducing IL-1 concentration in tissue, local application of ACS rich with IL-1Ra protein can have a negative influence on the complete blood count even after 4 weeks. The control group had normal neutrophil count but an increased platelet count due to the increased level of IL-1 concentration and its positive effect on IL-6 concentration. Subsequently, increased IL- 6 concentration could cause higher production of platelets. Despite blood changes in the irap group, no significant clinical changes were observed. Neutropaenia did not cause increased infection rate. Local irritation on ACS application sites disappeared within 5 days. Interleukin-1 receptor antagonist protein can be used for the treatment of tendon inflammation without serious health hazard in rabbits. The increased platelet count due to the larger quantity of IL-1 should be investigated in future studies. More precise studies should be conducted on the long-term use of IL-1Ra in tissue inflammatory treatment.

\section{References}

Archetti I, Tittarelli C, Cerioli M, Brivio R, Grilli G, Lavazza A 2008: Serum chemistry and hematology values in commercial rabbits: Preliminary data from industrial farms in northern Italy. Proceedings of 9th World Rabbit Congress, 10-13 July, Verona, Italy

Dhamija S, Kuehne N, Winzen R, Doerrie A, Dittrich-Breiholz O, Thakur BK, Kracht M, Holtmann H 2011: Interleukin-1 activates synthesis of interleukin-6 by interfering with a KH-type splicing regulatory protein (KSRP)-dependent translational silencing mechanism. J Biol Chem 286: 33279-33288

Evans CH, Gouye JN, Gouze E, Robbins PD, Ghivizzani SC 2004: Osteoarthritis gene therapy. Gene Ther 11: 379-389

Fernandes J, Tardif G, Martel-Pelletier J, Lascau-Coman V, Dupuis M, Moldovan F, Sheppard M, Krishnan BR, Pelletier JP 1999: In vivo transfer of interleukin-1 receptor antagonist gene in osteoarthritic rabbit knee joints: prevention of osteoarthritis progression. Am J Pathol 154: 1159-1169

Fleischmann RM, Schechtsman J, Bennett R, Handel ML, Burmester GR, Tesser J, Modafferi D, Poulakos J, Sun G 2003: Anakinra, a recombinant human interleukin-1 antagonist (r-metHuIL-1ra), in patients with rheumatoid arthritis. Arthritis Rheum 48927-48934

Friedrich T, Schmidt W, Jugmichel D, Horn LC, Josten CH 2011: Histopathology in rabbit Achilles tendon after operative tendolysis (longitudinal fiber incision). Scan J of Med and Sci in Sport 11: 4-8

Frisbie DD, Ghivizzani SC, Robbins PD, Evans CH, McIlwraith CW 2002: Treatment of experimental equine osteoarthritis by in vivo delivery of the equine interleukin-1 receptor antagonist gene. Gene Ther 9: 12-20

Fudge AM 1999: Laboratory Medicine: Avian and Exotic Pets. WB Saunders Co, Philadelphia.

Harkness JE, Wagner JE 1995: The Biology and Medicine of Rabbits and Rodents, Lea\&Febiger, Philadelphia.

Hewitt CD, Innes DJ, Savory J, Wills MR 1989: Normal biochemical and hematological values in New Zealand white rabbits. Clin Chem 35: 1777-1779

Jain NC 1986: Hematologic techniques. Veterinary Hematology. Lea\&Febiger, Philadelphia, pp 80-86

Kaser A, Brandacher G, Steurer W, Kaser S, Offner FA, Zoller H, Theurl I, Widder W, Molnar C, Ludwiczek O, Atkins MB, Mier JW, Til H 2001: Interleukin-6 stimulates thrombopoiesis through thrombopoietin: role in inflammatory thrombocytosis. Blood Journal 98: 2720-2725 
Kerr M 1989: Veterinary Laboratory Medicine. Clinical Biochemistry and Haematology. Blackwell Scientific Publications

Kos J, Radisic B, Smolec O, Brkljaca-Bottegaro N, Kreszinger M, Pecin M 2012: Molecular therapy of osteoarthritis horses and dogs with autologous proteins. Conference proceedings of 5th Croatian Veterinary Congress, Tuheljske toplice, Croatia. pp 415-422

Melillo A 2007: Rabbit clinical pathology. J Exot Pet Med 16: 135-146

Mirutka BM and Rawnley HM 1977: Clinical biochemical and haematological reference values in normal and experimental animals. Masson Publishing USA, Inc. 83: 134-135

Pelletier JP, Caron JP, Evans C, Robbins PD, Georgescu HI, Jovanović D, Fernandes JC, Martel-Pelletier J 1997: In vivo supression of early experimental osteoarthritis by interleukin-1 receptor antagonist using gene therapy. Arthritis Rheum 40: 1012-1019

Perlmutter RM, Bear M, Bekker P, Cohen S 2001: Anakinra for the Treatment of Rheumatoid Arthritis. Presentation of FDA, $16^{\text {th }}$ August. Published on Web URL: http:/www.fda.gov/ohrms/dockets/ac/01/slides/3779s1_01_ amgen.ppt

Rees JD, Wilson AM, Wolman RL 2006: Current concepts in the management of tendon disorders. Rheumatology 45: $508-521$

Ruble RP, Cullor JS, Brooks DL 1999: The observation of reactive thrombocytosis in New Zealand white rabbits in response to experimental Pasteurella multocida infection. Blood Cells Mol Dis 25: 95-102

Shi J, Goodband RD, Chengappa MM, Nelssen JL, Tokach MD, Mcvey DS, Blecha F 1994: Influence of interleukin-1 on neutrophil function and resistance to Streptococcus suis in neonatal pigs. J Leukoc Biol 56: 88-94

Textor J 2011: Autologous biologic treatment for equine musculoskeletal injuries: platelet-rich plasma and IL-1 receptor antagonist protein. Vet Clin North Am Equine Pract 27: 275-298

Tosato G and Jones KD 1990: Interleukin-1 induces interleukin-6 production in peripheral blood monocytes. Blood 75: 1305-1310

Vennen KM, Mitchell MA 2009: Rabbits. Manual of Exotic Pet Practice, W.B. Saunders, St. Louis, pp 375-405

Wehling P, Moser C, Frisbie D, Mcilwraith CW, Kawack CE, Krauspe R, Reinecke JA 2007: Autologous conditions serum in the treatment of orthopaedic diseases. Biodrugs 21: 323-332

Wright-Carpenter T, Opolon P, Appell HJ, Meijer H, Wehling P, Mir LM 2004: Treatment of muscle injuries by local administration of autologous conditioned serum: animal experiments using a muscle contusion model. Int J Sports Med 25: 582-587

Zhang B, Hu J, Man C, Zhu S 2011: Effect of intra-articular administration of interleukin 1 receptor antagonist on cartilage repair in temporomandibular joint. J Craniofac Surg 22: 711-714 